\title{
Satisfaction with Quality of Sexual and Reproductive Health Services Provided by Governmental Health Care System in the Gaza Strip, Palestine
}

\author{
Nasser I. Abu-El-Noor ${ }^{1, *}$, Bettina Bottcher ${ }^{2}$, Mysoon K. Abu-El-Noor ${ }^{3}$ \\ ${ }^{1}$ Faculty of Nursing, Islamic University of Gaza \\ Gaza, Palestine \\ Email: naselnoor [AT] iugaza.edu.ps \\ ${ }^{2}$ Faculty of Medicine, Islamic University of Gaza \\ Gaza, Palestine \\ Email: bettina.bottcher [AT] yahoo.co.uk \\ ${ }^{3}$ Faculty of Nursing, Islamic University of Gaza \\ Gaza, Palestine \\ Email: maziz [AT] iugaza.edu.ps \\ ${ }^{*}$ Corresponding author: Nasser I. Abu-El-Noor
}

\begin{abstract}
ABSTARCT----
Background and aim: In our dynamically changing world, incorporating patients' perception into quality assessment and assessing clients' satisfaction about provided services became a major component in the healthcare mission. The aim of this study is to assess clients' satisfaction with sexual and reproductive health services provided by governmental primary health care centers in the Gaza Strip.
\end{abstract}

Methods: A cross-sectional, descriptive design was used. A total of 128 clients who used sexual and reproductive healthcare services provide by governmental primary health care centers completed a survey that was prepared by the research team.

Results: The majority of participants (77.3\%) were satisfied with the services they received. Most of the items of the questionnaire received scores close to the neutral point of 3 on a Likert scale of 1-5. The only demographic variable that influenced participants' level of satisfaction was age.

Conclusion: Although the majority of participants in this study were satisfied with the sexual and reproductive health services they received, the mean scores for most items of the questionnaire were around the neutral point of three. This should be an impetus for healthcare policy makers and healthcare providers to work harder to improve quality of provided healthcare services, and thus; improving clients' satisfaction with provided services.

Keyword--- Client satisfaction, Sexual and reproductive health, Antenatal care, Postnatal care, Gaza Strip, Palestine

\section{INTRODUCTION}

Pregnancy and childbearing are unique experiences for each mother. The ultimate goals of this experience are to have safe and good outcomes without complications for the mother and her baby. Unfortunately, undesired complications may occur during pregnancy, labor or after delivery. These complications can be mild, moderate or in some cases severe enough to endanger the mother's or baby's lives (Böttcher, Abu-El-Noor, Aldabbour, Naim, \& Aljeesh, 2018; Hailu, 2014; Kikuchi et al., 2018; Lawn et al., 2014; World Health Organization, 2011).

According to the World Health Organization (WHO), about 830 women die from pregnancy- or childbirth-related complications around the world every day (WHO, 2016). This number decreased to 810 in 2017(WHO, 2019). Unfortunately, about $99 \%$ of these deaths are from low- and middle-income countries (Miller et al., 2016). On the other hand; 3.3 - 4 million neonatal deaths and 2.6 million third trimester stillbirths occur every year (Black et al., 2010; Lawn et al., 2014; Lawn, Cousens, \& Zupan, 2005; Lawn, Cousens, Zupan, \& Team, 2005; Lawn et al., 2009; Lozano et al., 2011; Oestergaard et al., 2011), with most of these death coming from low- and middle-income countries (Liu et al., 2015). In order to curb these high mortality rates, the WHO recommends improving skilled care during the time of pregnancy, 
childbirth and in the immediate postnatal period (WHO, 2009). Providing timely, high quality care after delivery will help to reduce maternal and neonatal morbidity and mortality rates. This enables health care providers to detect and treat complications early and minimizing their consequences (Böttcher et al., 2018).

In order to achieve good outcomes during and after pregnancy, provided services should be of high quality (Simkhada, Teijlingen, Porter, \& Simkhada, 2008). There are several definitions of quality of care but the Institute of Medicine (IOM) defines it as: "The degree to which health services for individuals and populations increase the likelihood of desired health outcomes and are consistent with current professional knowledge" (Institute of Medicine, 2001). On the other hand, the Agency for Health Care Research and Quality (AHRQ) defines it as "doing the right thing for the right patient at the right time in the right way to achieve the best possible result" (Agency for Healthcare Research and Quality, 2017).

In our dynamically changing world, healthcare industries strive for continuous quality improvement; which has gained a great concern in health care arena in recent years. Therefore; incorporating patients' perception into quality assessment and assessing clients' satisfaction about provided service/s became a major component in the healthcare mission (Al-Abri \& Al-Balushi, 2014). This motivated healthcare managers, who strive to achieve excellence, to take patient perception into account when designing the strategies for quality improvement of care. Therefore; patient satisfaction surveys became an important quality improvement tool for improving organizational performance (Marley, Collier, \& Meyer Goldstein, 2004) and an important indicator for improving the services and strategic goals for all healthcare organizations (Elaine, Gail, \& Richard, 2002). Moreover, Gregory, Heaman, Mignone, and Moffatt (2019) found out a strong link between quality of care and client's satisfaction. Specifically, they found that quality of prenatal care and provider interpersonal style together explained $80 \%$ of the variance in overall clients' satisfaction about provided services. On the other hand, a study conducted by Boyer, Francois, Doutre, Weil, and Labarere (2006) revealed that $94 \%$ of clinical staff in a French hospital think that patients were able to judge hospital service quality, especially in its relational, organizational and environmental dimensions.

In the Gaza strip, most of the health services related to sexual and reproductive health (SRH) are provided for free of charge. Most of these services are provided in primary health care centers. These services include antenatal care, postnatal care and family planning. The aim of this study is to assess clients' satisfaction with quality of sexual and reproductive services provided by governmental primary health care centers in the Gaza Strip.

\section{METHODOLOGY}

\section{Study design}

This study used a descriptive, cross sectional design.

\section{Study population and setting}

The population of the study included all adult females who received services related to SRH offered by governmental primary health care centers (PHCC). These services include antenatal care, postnatal care and family planning. The Gaza Strip consists of five governorates; each governorate has several PHCCs. Two main PHCC from two different governorates were chosen randomly.

\section{Sample and sampling method}

A convenience sample of 128 (64 from each PHCC) participants was used in this study. Inclusion criteria included women who were 18 years or older, who utilizes any of the SRH services offered by PHCC that belong to the governmental healthcare system which is the major healthcare provider in the Gaza Strip.

\section{Instrument}

After reviewing the literature, the researchers developed a self-administered questionnaire to conduct this study. The questionnaire consisted of two parts. The first part was concerned about obtaining demographic characteristics of the participants. The second part consisted of 19 items that measures clients' satisfaction about the provided services. The items were rated on a 5 -point Likert scale $(1=$ completely disagree, $2=$ disagree, $3=$ neutral, $4=$ agree, and $5=$ strongly agree)

To ensure the content validity of the instrument, it was reviewed by five experts in the field who suggested slight modifications. After modifying the instrument it was pilot-tested by a sample of 10 women who met the inclusion criteria and were selected randomly from the targeted PHCCs. The data obtained from these clients were not included in the study. 
Slight modifications were done on the wording of some items in response to participants' comments to make the instrument more user friendly for participants. The instrument showed that it was highly reliable with a Cronbach's alpha of 0.939 for the entire instrument (Streiner, 2003)

\section{Data collection}

To avoid bias, data were collected by trained nurses who are not were not working at the involved PHCCs. Each questionnaire included a front sheet that explained the purpose of the study and a consent form for the participants to sign.

\section{Data analysis}

Data was entered and analyzed using SPSS version 22. Before analysis, data was checked to ensure accuracy of data entry. Descriptive statistics including percentages, means, and standard deviations, were used for all items of the questionnaire. ANOVA and t-tests were used to compare means. These analyses used a $95 \%$ confidence interval and a significance level of 0.05 .

\section{Ethical considerations}

Before starting the study, approval to conduct the study was obtained from the research ethics committee at the Islamic University of Gaza and from the Ministry of Health. Participants were asked to sign an informed consent that was included in the first page of the questionnaire. The consent stated the purpose of the study as well as the voluntary nature of participation and confidentiality of the information gathered. Participants were told that they had the right to refuse participation in the study without any consequence or effect on the care they received.

\section{RESULTS}

\section{Demographic characteristics of the participants}

Demographic characteristics of the participants are presented in table 1. The age of participants ranged from 18 to 47 years with a mean of $27.4( \pm 6.8)$ years. The majority of participants fall within the age category between 21 and 30 years $(\mathrm{N}=83$, $64.8 \%)$. Furthermore, most participants were well educated and either had a university degree $(\mathrm{N}=57,44.5 \%)$ or reached secondary school $(\mathrm{N}=66,51.5 \%)$. Half of the participants visited the two PHCCs to receive antenatal care $(\mathrm{N}=64.5,50 \%)$ followed by family planning services $(\mathrm{N}=44,34.4 \%)$. The length of time participants used the services at the two centers ranged from three weeks to 7 years. More than half of the participants $(\mathrm{N}=59,48.8 \%)$ were using the services of the centers for more than three years (table 1).

Table 1: Descriptive statistics of characteristics of participants

\begin{tabular}{|c|c|c|c|c|}
\hline \multicolumn{2}{|c|}{ Variable } & PHCC 1 & PHCC 2 & Total \\
\hline \multicolumn{2}{|c|}{ Number of participants } & $64(50.0 \%)$ & $64(50 \%)$ & 128 \\
\hline \multirow{4}{*}{ 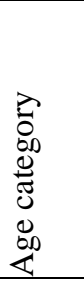 } & $\leq 20$ year & $7(58.3 \%)$ & $5(41.7 \%)$ & $12(9.4 \%)$ \\
\hline & $21-30$ & $41(49.4 \%)$ & $42(50.6 \%)$ & $83(64.8 \%)$ \\
\hline & $31-40$ & $16(64.0 \%)$ & $9(36.0 \%)$ & $25(19.5 \%)$ \\
\hline & $41-50$ & $0(.0 \%)$ & $8(100 \%)$ & $8(6.3 \%)$ \\
\hline \multirow{3}{*}{ 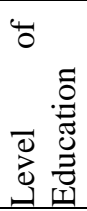 } & Preparatory school & $3(60.0 \%)$ & $2(40.0 \%)$ & $5(3.9 \%)$ \\
\hline & Secondary School & $38(57.6 \%)$ & $28(42.4 \%)$ & $66(51.6 \%)$ \\
\hline & University & $23(40.4 \%)$ & $34(59.6 \%)$ & $57(44.5 \%)$ \\
\hline \multirow{4}{*}{ 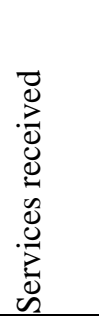 } & Antenatal care & $41(64.1 \%)$ & $23(35.9 \%)$ & $64(50.0 \%)$ \\
\hline & Family planning & $15(34.1 \%)$ & $29(65.9 \%)$ & $44(34.4 \%)$ \\
\hline & $\begin{array}{l}\text { Reproductive Health } \\
\text { Advice }\end{array}$ & $1(33.3 \%)$ & $2(66.7 \%)$ & $3(2.3 \%)$ \\
\hline & Postnatal & $5(62.5 \%)$ & $3(37.5 \%)$ & $8(5.3 \%)$ \\
\hline
\end{tabular}




\begin{tabular}{|c|c|c|c|c|}
\hline & More than 1 service & $1(12.5 \%)$ & $7(87.5 \%)$ & $8(5.3 \%)$ \\
\hline & Others & $1(100 \%)$ & $0(0.0 \%)$ & $1(0.8 \%)$ \\
\hline \multirow{2}{*}{$\begin{array}{l}\stackrel{\infty}{:} \\
\stackrel{=}{0}\end{array}$} & $<6$ months & $7(58.3 \%)$ & $5(41.7 \%)$ & $12(9.9 \%)$ \\
\hline & 6-11 months & $11(78.6 \%)$ & $3(21.4 \%)$ & $14(21.5 \%)$ \\
\hline \multirow{2}{*}{ 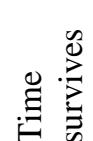 } & $1-3$ years & $22(61.1 \%)$ & $14(28.9 \%)$ & $36(51.2 \%)$ \\
\hline & $>3$ years & $23(39.0 \%)$ & $36(61.0 \%)$ & $59(48.8 \%)$ \\
\hline
\end{tabular}

\section{Satisfaction about provided services}

Level of satisfaction among participants in the two PHCCs is presented in table 2. The two items that received the highest scores among participants from the two centers were "Staff are willing to listen carefully and help clients (mean = 3.3)" followed by "I like to return to this center if I need the same services in the future (mean $=3.3$ )".

The two items that received the highest scores among participants from the first PHCC were "I will recommend this health center for my friends and relatives" and "Staff are willing to listen carefully and help clients" as they get scores of 3.4 and 3.43 respectively. The item that received the lowest score among participants from first PHCC was "The waiting time to see the health care professional is convenient" as it received a score of 3.1.

The two items that received the highest scores among participants from the second PHCC were "The healthcare center is in a convenient location that is easily reached" and "Staff are willing to listen carefully and help clients" with scores of 3.2 and 3.2 respectively. The item with the lowest score among participants from the second PHCC was "Staff understand my specific needs" with a score of 2.9 (table 2).

In general, scores reported by participants who used the first PHCC were higher than scores reported by participants from the second PHCC in each of the 19 items with nine items showing statistical significance between their means (table 2). Moreover, the total score of satisfaction reported by participants using SRH services provided by the first PHCC (63.0) was higher than scores reported by participants using SRH services provided by the second PHCC (58.5). These differences were found to be statistically significant $(\mathrm{p}=0.014)$.

Table 2: Level of satisfaction about provided SRH services

\begin{tabular}{|c|c|c|c|c|}
\hline & $\begin{array}{l}\text { Total } \\
\mathrm{N}=128\end{array}$ & $\begin{array}{l}\text { PHCC } 1 \\
\mathrm{~N}=64\end{array}$ & $\begin{array}{c}\mathrm{PHCC} 2 \\
\mathrm{~N}=64\end{array}$ & P value \\
\hline 1. The physical facility is clean and comfortable & 3.12 & 3.13 & 3.11 & 0.899 \\
\hline $\begin{array}{l}\text { 2. The health care center is in a convenient location } \\
\text { that is easily reached }\end{array}$ & 3.26 & 3.27 & 3.24 & 0.825 \\
\hline 3. The time spent by the healthcare provider is adequate & 3.10 & 3.206 & 2.98 & 0.046 \\
\hline 4. Staff provides services at convenient times. & 3.10 & 3.18 & 3.02 & 0.167 \\
\hline 5. There is a good appointment system to clients & 3.10 & 3.16 & 3.03 & 0.280 \\
\hline 6. $\quad$ Sufficient staff are always available & 3.08 & 3.18 & 2.98 & 0.151 \\
\hline 7. My questions and concerns are handled responsibly. & 3.22 & 3.37 & 3.07 & 0.013 \\
\hline 8. Staff are willing to listen carefully and help clients. & 3.32 & 3.43 & 3.19 & 0.043 \\
\hline 9. The staff are responsive to clients' needs. & 3.26 & 3.41 & 3.09 & 0.003 \\
\hline 10. The staff are supportive and empathetic with clients. & 3.24 & 3.32 & 3.16 & 0.169 \\
\hline $\begin{array}{l}\text { 11. I feel that staff have enough knowledge to deal with } \\
\text { my questions. }\end{array}$ & 3.24 & 3.40 & 3.07 & 0.010 \\
\hline 12. Staff understand my specific needs & 3.07 & 3.21 & 2.91 & 0.016 \\
\hline 13. I feel comfortable and trust in my healthcare provider & 3.23 & 3.31 & 3.14 & 0.190 \\
\hline $\begin{array}{l}\text { 14. The health information was provided in a clear and } \\
\text { understandable language }\end{array}$ & 3.22 & 3.31 & 3.12 & 0.164 \\
\hline
\end{tabular}




\begin{tabular}{|l|l|l|l|l|}
\hline 15. My privacy is respected in this health care center. & 3.19 & 3.24 & 3.14 & 0.437 \\
\hline $\begin{array}{l}\text { 16. The waiting time to see the health care professional is } \\
\text { convenient }\end{array}$ & 3.07 & 3.11 & 3.02 & 0.439 \\
\hline $\begin{array}{l}\text { 17. Overall, I am satisfied with services provided by this } \\
\text { clinic. }\end{array}$ & 3.17 & 3.31 & 3.02 & 0.012 \\
\hline $\begin{array}{l}\text { 18. I will recommend this health center for my friends and } \\
\text { relatives }\end{array}$ & 3.26 & 3.44 & 3.05 & 0.002 \\
\hline $\begin{array}{l}\text { 19. I like to return to this center if I need the same services } \\
\text { in the future }\end{array}$ & 3.28 & 3.41 & 3.15 & 0.018 \\
\hline Mean of total score & $\mathbf{3 . 1 8 1}$ & $\mathbf{3 . 3 1 7}$ & $\mathbf{3 . 0 7 7}$ & $\mathbf{0 . 0 1 4}$ \\
\hline
\end{tabular}

To calculate percentage of satisfied clients with SRH services, any participant who had a mean of the total score $\geq 3$ was considered to be satisfied while any participant who had a score $<3$ was considered dissatisfied. After dichotomizing the mean scores for satisfaction, results revealed that $77.3 \%(n=99)$ of participants and $22.7 \%(n=29)$ participants were not satisfied with the services they received. The difference between the mean scores of satisfaction among satisfied participants $(3.36 \pm 0.29)$ and those who were not $(2.95 \pm 2.56)$ were statistically significant $(\mathrm{p}=0.003)$

\section{Impact on level of satisfaction}

Result of ANOVA (table 3) showed that level of education of participants, type of service used, and length of time using provided services by PHCC had no impact of clients' level of satisfaction. The only variable that showed to have an association with participants' satisfaction was age $(\mathrm{p}=0.006)$. The older age group of 41-50 years old participants gave a significantly lower score in total satisfaction compared with the younger groups, especially those in the 31-40 years group $(\mathrm{p}=0.009)$.

Table 3: Factors that impact level of satisfaction

\begin{tabular}{|l|l|l|l|}
\hline Variable & Mean & SD & P value \\
\hline Age & & & 0.006 \\
$\quad \leq 20$ & 60.826 & 8.783 & \\
$21-30$ years & 60.353 & 8.405 & \\
$31-40$ years & 64.669 & 5.256 & \\
$41-50$ years & 52.861 & 13.506 & \\
\hline Level of Education & & & 0.218 \\
$\quad$ Preparatory school & 66.882 & 7.055 & \\
Secondary school & 60.872 & 9.371 & \\
University & 59.680 & 8.651 & \\
\hline Service received & & & 0.377 \\
Antenatal care & 61.3666 & 8.75081 & \\
Family planning & 58.6582 & 8.19717 & \\
Reproductive health advice & 66.2887 & 5.14956 & \\
Postnatal & 58.2661 & 8.89025 & \\
More than 1 service & 61.6919 & 15.16710 & \\
\hline Time of service & & & 0.707 \\
$\quad$ < 6 months & 60.1703 & 10.53175 & \\
6-11 months & 62.9540 & 6.10285 & \\
1-3 years & 59.8096 & 7.70935 & \\
> 3 years & 60.9451 & 9.38329 & \\
\hline
\end{tabular}

\section{DISCUSSION}

Our results revealed a moderate satisfaction with provided SRH services provided by governmental PHCCs as most of the variables were around the neutral points of three and that $77.3 \%$ of participants were satisfied about the services they received. Studies about this topic in Palestine are rare. One study was conducted in the West Bank of Palestine compared level of satisfaction of women for SRH services who used the midwife-led continuity model and who received regular care (Mortensen et al., 2019). The results revealed that women who used the midwife-led continuity model were somewhat more satisfied than women who received normal care. Anyhow; both groups rated their level of satisfaction as moderate. The scores were 5.2 versus 4.8 respectively on a Likert scale of 1-7. 
Studies came from other parts of the globe reported different levels of satisfaction about services related to maternal care. In a study conducted in Sweden, the majority of participants were satisfied with their antenatal care, but $23 \%$ were dissatisfied with the emotional aspects and $18 \%$ with the medical aspects of the care they received. The strongest predictors of dissatisfaction were women's opinions that midwives had not been supportive and had not paid attention to their partners' needs (Hildingsson \& Rådestad, 2005).

Studies from Iran showed variable results. In a study conducted by Mesgarzadeh, Baghaei, Ebrahimi, and Orujlu (2014), results revealed that levels of satisfaction were $77.17 \%$ with prenatal care and $77.49 \%$ with postpartum care. The authors of another study conducted in Turkey described level of their participants as 'somewhat satisfied' with the prenatal care service. The mean scores for the domains of their study ranged between 3.3 to 3.7 on a 4-point Likert scale (Erci \& Ivanov, 2004), which is slightly higher than the means reported in our study.

Other studies from developing countries that explored clients' satisfaction with antenatal care services varied from one country to the other. Some studies reported a higher level of satisfaction compared to our results. Examples include studies came from Cameroon (Edie et al., 2015), Kenya (Vo et al., 2012), and two studies from Nigeria (Onyeajam, Xirasagar, Khan, Hardin, \& Odutolu, 2018) and (Nwaeze, Enabor, Oluwasola, \& Aimakhu, 2013) which reported that 96.4\%, 95\%, $90 \%, 81.1 \%$ of their clients, respectively, were satisfied with the antenatal care they received. Other studies from other developing countries reported less level of satisfaction about antenatal services: 68\% (Lakew, Ankala, \& Jemal, 2018) and $60 \%$ (Chemir, Alemseged, \& Workneh, 2014) from Ethiopia and 59\% from Oman (Ghobashi \& Khandekar, 2008).

Satisfaction with SRH services is multidimensional, dynamic and influenced by a variety of different factors (Bernitz, Øian, Sandvik, \& Blix, 2016; Britton, 2012). This study found no impact of sociodemographic variables, with the exception of age, on level of satisfaction with received SRH care with women aged $>41$ years being least satisfied. This result contradicts the results of Hoseini, Saeidi, Beheshti Norouzi, Kiani, and Rakhshani (2019) and results of Mesgarzadeh et al. (2014). The authors believe that older women had more experience with received SRH care, therefore; their expectations will be higher than younger women's expectations who have less experience. Similarly, Mirzaei, Oladi Ghadikolaee, Mousavi Bazzaz, and Ziaee (2016) reported that there was no significant association between level of participants' satisfaction about postnatal care and variables such as parity, age and number of children. Also, Wiegers (2009) reported that parity did not influence rating of participants about quality of postnatal care they received. On the other hand, other studies found that sociodemographic factors influenced the level of satisfaction related to maternal care. Lower levels of satisfaction were associated with less educational attainments, young age, and primiparity (Ahmadi \& Azimi, 2009; Britton, 2012; Naghizadeh, Rezaie, Sehhati, Barzanje, \& Ebrahimi, 2014; Sachsanidis, 2018; Waldenström, Rudman, \& Hildingsson, 2006).

However, other determinants of clients' satisfaction with SRH services were found in a literature review of studies from low-income countries that revealed 'being treated with respect', in terms of courtesy and non-abuse, irrespective of sociocultural or economic context, was especially important to women and increased their satisfaction (Srivastava, Avan, Rajbangshi, \& Bhattacharyya, 2015). Similarly, in this study, items related to staff communication ('My questions and concerns are handled responsibly' and 'Staff are willing to listen carefully and help clients') and support ('The staff are supportive and empathetic with clients') received relatively higher scores, impacting the overall satisfaction scores. Moreover, literature found that interpersonal behavior was the most prominent reported determinant of maternal satisfaction and it was more important than structural factors such as cleanliness and physical environment (Srivastava et al., 2015). This, along with results from our study, proved that interaction between clients and health care providers were important determinants of women's level of satisfaction. Similar results supporting this notion were reported by other studies (Birhanu, Assefa, Woldie, \& Morankar, 2010; Chavane et al., 2017; Nabbuye-Sekandi et al., 2011).

Handler, Rosenberg, Raube, and Lyons (2003) reported that spending more time with pregnant women, explaining procedures to them asking them questions and answering their questions, along with clean, comfortable waiting areas were the most factors that improved pregnant women's satisfaction about the care they receive. These results are congruent with the results of this study, as the score for items pertaining to communication, listening to and answering clients question were relatively higher than the neutral point of three; reflecting the importance of listening to participants. Other studies supported the importance of convenient clinic hours, privacy during consultation, trust in healthcare providers and staff empathy as determinants for clients' satisfaction with services related to SRH (Lakew et al., 2018; Onyeajam et al., 2018). Many other studies corroborate the positive association of effective provider communication with clients' satisfaction with antenatal care services (Korenbrot, Wong, \& Stewart, 2005; Lakew et al., 2018; Onyeajam et al., 2018; Vo et al., 2012; Wachira, Middlestadt, Reece, Peng, \& Braitstein, 2014).

To improve level of clients' satisfaction with SRH service, it is empirical to improve quality of these services. Especially that some studies found that quality is positively correlating with clients' satisfaction (Boyer et al., 2006; Gregory et al., 
2019; Onyeajam et al., 2018). Therefore; it is important to improve quality of SRH provided to clients in the Gaza Strip. This is in spite that previous two studies reported a high quality of antenatal care (Abu-El-Noor et al., 2018) and a relatively high quality of postnatal care in the Gaza Strip (Alkasseh, Mwafy, Abu-El-Noor, \& Abu-El-Noor, In Press). But; it's worthy to notice that the quality of antenatal care study has evaluated the perception of nurses and midwives who are providing these services about quality of antenatal care. The discrepancy between clinicians' and patients' ratings of health status and quality of care is well documented in the literature (Janse et al., 2004).

\section{CONCLUSIONS}

This study revealed that $77.3 \%$ of participants were satisfied with received SRH services. Most of the scores for the items used in the study were around the neutral points of three. Healthcare providers and health policy makers need to improve clients' satisfaction. This could be reached through improving quality of these services as evidence coming from research supports the positive correlation between quality of provided services and clients' satisfaction.

\section{REFERENCES}

- $\quad$ Abu-El-Noor, N. I., Abu-Sultan, N., Alkasseh, A. S., El-Shokry, M., Fareed, M., \& Saleh, K. (2018). Quality of antenatal Care in Governmental Primary Health Care Centers in the Gaza strip as perceived by nurses and midwives: an indication for policy change. IUG Journal of Natural Studies, 26(2).

- Agency for Healthcare Research and Quality. (2017). A Quick Look at Quality. Retrieved 13/07, 2017, from https://archive.ahrq.gov/consumer/qnt/qntqlook.htm

- Ahmadi, Z., \& Azimi, H. (2009). Evaluation of mothers' satisfaction with midwifery cares received in the delivery room. Scientific Journal of Hamadan Nursing \& Midwifery Faculty, 19(67), 30-35.

- Al-Abri, R., \& Al-Balushi, A. (2014). Patient satisfaction survey as a tool towards quality improvement. Oman medical journal, 29(1), 3.

- Alkasseh, A. S., Mwafy, S., Abu-El-Noor, N., \& Abu-El-Noor, M. (In Press). Assessing the quality of postnatal care provided at government hospitals in the Gaza Strip, Palestine as perceived by service users: a direction for policy change. Holistic Nursing \& Midwifery Journal.

- $\quad$ Bernitz, S., Øian, P., Sandvik, L., \& Blix, E. (2016). Evaluation of satisfaction with care in a midwifery unit and an obstetric unit: a randomized controlled trial of low-risk women. BMC pregnancy and childbirth, 16(1), 143.

- Birhanu, Z., Assefa, T., Woldie, M., \& Morankar, S. (2010). Determinants of satisfaction with health care provider interactions at health centres in central Ethiopia: a cross sectional study. BMC health services research, 10(1), 78.

- Black, R. E., Cousens, S., Johnson, H. L., Lawn, J. E., Rudan, I., Bassani, D. G., . . Cibulskis, R. (2010). Global, regional, and national causes of child mortality in 2008: a systematic analysis. The Lancet, 375(9730), 1969-1987.

- Boyer, L., Francois, P., Doutre, E., Weil, G., \& Labarere, J. (2006). Perception and use of the results of patient satisfaction surveys by care providers in a French teaching hospital. International journal for quality in health care, 18(5), 359-364.

- $\quad$ Britton, J. R. (2012). The assessment of satisfaction with care in the perinatal period. Journal of Psychosomatic Obstetrics \& Gynecology, 33(2), 37-44.

- $\quad$ Böttcher, B., Abu-El-Noor, N., Aldabbour, B., Naim, F. N., \& Aljeesh, Y. (2018). Maternal mortality in the Gaza strip: a look at causes and solutions. BMC pregnancy and childbirth, 18(1), 396.

- Chavane, L., Dgedge, M., Bailey, P., Loquiha, O., Aerts, M., \& Temmerman, M. (2017). Assessing women's satisfaction with family planning services in Mozambique. J Fam Plann Reprod Health Care, 43(3), 222-228.

- Chemir, F., Alemseged, F., \& Workneh, D. (2014). Satisfaction with focused antenatal care service and associated factors among pregnant women attending focused antenatal care at health centers in Jimma town, Jimma zone, South West Ethiopia; a facility based cross-sectional study triangulated with qualitative study. BMC research notes, 7(1), 164.

- $\quad$ Edie, G. E. H. E., Obinchemti, T. E., Tamufor, E. N., Njie, M. M., Njamen, T. N., \& Achidi, E. A. (2015). Perceptions of antenatal care services by pregnant women attending government health centres in the Buea Health District, Cameroon: a cross sectional study. Pan African Medical Journal, 21(1).

- $\quad$ Elaine, Y., Gail, C., \& Richard, R. (2002). The Measurement of Patient Satisfaction Journal Nurse Care Quality.

- Erci, B., \& Ivanov, L. (2004). The relationship between women's satisfaction with prenatal care service and the characteristics of the pregnant women and the service. The European Journal of Contraception \& Reproductive Health Care, 9(1), 16-28.

- Ghobashi, M., \& Khandekar, R. (2008). Satisfaction among expectant mothers with antenatal care services in the Musandam Region of Oman. Sultan Qaboos University Medical Journal, 8(3), 325.

- Gregory, P. A., Heaman, M. I., Mignone, J., \& Moffatt, M. E. (2019). Predictors of Women's Satisfaction with Prenatal Care in a Canadian Setting. Maternal and Child Health Journal, 1-10. 
- Hailu, Y. (2014). Factors Affecting Utilization of Postnatal Care Service in Amhara Region, Jabitena District, Ethiopia. Science Journal of Public Health, 2(3), 169-176.

- Handler, A., Rosenberg, D., Raube, K., \& Lyons, S. (2003). Prenatal care characteristics and African-American women's satisfaction with care in a managed care organization. Women's Health Issues, 13(3), 93-103.

- Hildingsson, I., \& Rådestad, I. (2005). Swedish women's satisfaction with medical and emotional aspects of antenatal care. Journal of Advanced Nursing, 52(3), 239-249.

- Hoseini, B. L., Saeidi, M., Beheshti Norouzi, Z., Kiani, M. A., \& Rakhshani, M. H. (2019). Assessment of Maternal Satisfaction with the Quality of Obstetric Care Provided in the Maternity Unit of Mobini Hospital, Sabzevar, Iran. International Journal of Pediatrics, 7(5), 9369-9377.

- Institute of Medicine. (2001). Crossing the Quality Chasm: A New Health System for the 21st Century. Washington, D.C.: National Academy Press.

- Janse, A., Gemke, R., Uiterwaal, C., Van Der Tweel, I., Kimpen, J., \& Sinnema, G. (2004). Quality of life: patients and doctors don't always agree: a meta-analysis. Journal of clinical epidemiology, 57(7), 653-661.

- Kikuchi, K., Yasuoka, J., Nanishi, K., Ahmed, A., Nohara, Y., Nishikitani, M., . . . Nakashima, N. (2018). Postnatal care could be the key to improving the continuum of care in maternal and child health in Ratanakiri, Cambodia. PLoS One, 13(6), e0198829.

- Korenbrot, C. C., Wong, S. T., \& Stewart, A. L. (2005). Health promotion and psychosocial services and women's assessments of interpersonal prenatal care in Medicaid managed care. Maternal and Child Health Journal, 9(2), 135-149.

- $\quad$ Lakew, S., Ankala, A., \& Jemal, F. (2018). Determinants of client satisfaction to skilled antenatal care services at Southwest of Ethiopia: a cross-sectional facility based survey. BMC pregnancy and childbirth, 18(1), 479.

- $\quad$ Lawn, J. E., Blencowe, H., Oza, S., You, D., Lee, A. C., Waiswa, P., . . Christian, P. (2014). Every Newborn: progress, priorities, and potential beyond survival. The Lancet, 384(9938), 189-205.

- Lawn, J. E., Cousens, S., \& Zupan, J. (2005). Neonatal survival 1.4 million neonatal deaths: When? Where? Why? Lancet, 365(9462), 891-900.

- Lawn, J. E., Cousens, S., Zupan, J., \& Team, L. N. S. S. (2005). 4 million neonatal deaths: when? Where? Why? The Lancet, 365(9462), 891-900.

- $\quad$ Lawn, J. E., Lee, A. C., Kinney, M., Sibley, L., Carlo, W. A., Paul, V. K., . . Darmstadt, G. L. (2009). Two million intrapartum- related stillbirths and neonatal deaths: where, why, and what can be done? International Journal of Gynecology \& Obstetrics, 107(Supplement), S5-S19.

- $\quad$ Liu, L., Oza, S., Hogan, D., Perin, J., Rudan, I., Lawn, J. E., . . Black, R. E. (2015). Global, regional, and national causes of child mortality in 2000-13, with projections to inform post-2015 priorities: an updated systematic analysis. The Lancet, 385(9966), 430-440.

- $\quad$ Lozano, R., Wang, H., Foreman, K. J., Rajaratnam, J. K., Naghavi, M., Marcus, J. R., . . Atkinson, C. (2011). Progress towards Millennium Development Goals 4 and 5 on maternal and child mortality: an updated systematic analysis. The Lancet, 378(9797), 1139-1165.

- Marley, K. A., Collier, D. A., \& Meyer Goldstein, S. (2004). The role of clinical and process quality in achieving patient satisfaction in hospitals. Decision Sciences, 35(3), 349-369.

- Mesgarzadeh, M., Baghaei, R., Ebrahimi, M., \& Orujlu, S. (2014). Survuy of mother's satisfaction from provided care in delivery unit in the Khoy Qamar Bani Hashem hospital in 2012. The Journal of Urmia Nursing and Midwifery Faculty, 12(10), 919-925.

- Miller, S., Abalos, E., Chamillard, M., Ciapponi, A., Colaci, D., Comandé, D., . . Langer, A. (2016). Beyond too little, too late and too much, too soon: a pathway towards evidence-based, respectful maternity care worldwide. The Lancet, 388(10056), 2176-2192.

- $\quad$ Mirzaei, K., Oladi Ghadikolaee, S., Mousavi Bazzaz, M., \& Ziaee, M. (2016). Mother's satisfaction of postpartum care and its relationship with midwifery care at Urban Health Centers, Mashhad, Iran. Journal of Midwifery and Reproductive Health, 4(3), 679-688.

- Mortensen, B., Diep, L. M., Lukasse, M., Lieng, M., Dwekat, I., Elias, D., \& Fosse, E. (2019). Women's satisfaction with midwife-led continuity of care: an observational study in Palestine. BMJ open, 9(11).

- $\quad$ Nabbuye-Sekandi, J., Makumbi, F. E., Kasangaki, A., Kizza, I. B., Tugumisirize, J., Nshimye, E., . . . Peters, D. H. (2011). Patient satisfaction with services in outpatient clinics at Mulago hospital, Uganda. International journal for quality in health care, 23(5), 516-523.

- Naghizadeh, S., Rezaie, M. E. M., Sehhati, F., Barzanje, S. A., \& Ebrahimi, H. (2014). Assessment Mothers Satisfaction of postpartum care. Advances in Nursing \& Midwifery, 23(82), 71-78.

- Nwaeze, I., Enabor, O., Oluwasola, T., \& Aimakhu, C. (2013). Perception and satisfaction with quality of antenatal care services among pregnant women at the university college hospital, Ibadan, Nigeria. Annals of Ibadan postgraduate medicine, 11(1), 22-28. 
- $\quad$ Oestergaard, M. Z., Inoue, M., Yoshida, S., Mahanani, W. R., Gore, F. M., Cousens, S., .. Mathers, C. D. (2011). Neonatal mortality levels for 193 countries in 2009 with trends since 1990: a systematic analysis of progress, projections, and priorities. PLoS medicine, 8(8), e1001080.

- Onyeajam, D. J., Xirasagar, S., Khan, M. M., Hardin, J. W., \& Odutolu, O. (2018). Antenatal care satisfaction in a developing country: a cross-sectional study from Nigeria. BMC public health, 18(1), 368.

- Sachsanidis, P. I. (2018). Evaluating Women's Satisfaction With Health Services Received During Childbirth: A Study of Hospitals in Athens, Greece. Journal of Clinical Gynecology and Obstetrics, 7(1), 1-12.

- Simkhada, B., Teijlingen, E. R. v., Porter, M., \& Simkhada, P. (2008). Factors affecting the utilization of antenatal care in developing countries: systematic review of the literature. Journal of Advanced Nursing, 61(3), 244-260.

- Srivastava, A., Avan, B. I., Rajbangshi, P., \& Bhattacharyya, S. (2015). Determinants of women's satisfaction with maternal health care: a review of literature from developing countries. BMC pregnancy and childbirth, 15(1), 97.

- Streiner, D. L. (2003). Starting at the beginning: an introduction to coefficient alpha and internal consistency. Journal of personality assessment, 80(1), 99-103.

- Vo, B. N., Cohen, C. R., Smith, R. M., Bukusi, E. A., Onono, M. A., Schwartz, K., . . Turan, J. M. (2012). Patient satisfaction with integrated HIV and antenatal care services in rural Kenya. AIDS care, 24(11), 1442-1447.

- Wachira, J., Middlestadt, S., Reece, M., Peng, C.-Y. J., \& Braitstein, P. (2014). Physician communication behaviors from the perspective of adult HIV patients in Kenya. International journal for quality in health care, 26(2), 190-197.

- Waldenström, U., Rudman, A., \& Hildingsson, I. (2006). Intrapartum and postpartum care in Sweden: women's opinions and risk factors for not being satisfied. Acta obstetricia et gynecologica Scandinavica, 85(5), 551-560.

- WHO. (2009). Monitoring emergency obstetric care Retrieved from http://www.who.int/reproductivehealth/publications/monitoring/9789241547734/en/

- WHO. (2016). Maternal mortality: Fact sheet. http://www.who.int/mediacentre/factsheets/fs348/en/

- WHO. (2019). Maternal mortality. Retrieved 20,01, 2020, from https://www.who.int/news-room/factsheets/detail/maternal-mortality

- Wiegers, T. A. (2009). The quality of maternity care services as experienced by women in the Netherlands. $B M C$ pregnancy and childbirth, 9(1), 18.

- World Health Organization. (2011). WHO statement on antenatal care: Geneva: World Health Organization. 